\title{
A geopolítica das terras raras ${ }^{1}$
}

\author{
The Geopolitics of rare earths
}

DOI: $10.21530 /$ ci.v12n2.2017.634

Filipe Reis Melo²

\section{Resumo}

Variações de oferta e dificuldades de acesso a determinados produtos estratégicos podem provocar mudanças na geopolítica internacional. Os choques do petróleo ocorridos na década de 1970 são, talvez, os exemplos mais conhecidos de como a reconfiguração do poder entre os países pode ser redesenhada em função de quem detém determinado produto estratégico. Um conjunto de 17 metais, conhecidos como terras raras, que possui propriedades químicas únicas, está no centro de uma tensão comercial internacional desde que a China, que exporta cerca de $95 \%$ do mercado mundial de terras raras, passou a restringir suas exportações a partir de meados de 2000. Este artigo investiga as motivações políticas e econômicas que estiveram por trás do embate na Organização Mundial do Comércio (OMC) entre a China, de um lado, e os Estados Unidos, a União Europeia e o Japão, de outro, que denunciaram a China em 2012 por impor restrições à exportação de terras raras, e analisa como o Brasil poderia aproveitar o seu potencial como produtor de terras raras para fortalecer sua posição no cenário internacional. Conclui-se que o diferendo na OMC foi apenas o primeiro capítulo de uma história de tensões internacionais que estão por vir no cenário internacional.

Palavras-chave: Terras raras; OMC; China; Brasil

\begin{abstract}
Instability in supply and difficulties in reaching some strategic products can lead to changes in global geopolitics. The 1970s petroleum shock are, perhaps, the most recent examples of how the power between countries can be redefined by whom owns a particular strategic product. A set of seventeen metals known as rare earths, which has special chemical properties, is the core of international trade tension since China, which exports about $95 \%$ of the global rare earth market, began to restrict its exports from 2000s. This paper is about the political and

1 Pesquisa financiada pelo Edital MCTI/CNPq/MEC/CAPES nº 43/2013

2 Departamento de Relações Internacionais da Universidade Estadual da Paraíba, João Pessoa/PB, Brasil. E-mail: freismelo@yahoo.com

Artigo submetido em 12/02/2017 e aprovado em 03/05/2017.
\end{abstract}


economic motivations behind the dispute in the World Trade Organization (WTO) between on the one hand China, and on the other hand the United States, the European Union and Japan, which denounced China in 2012 by imposing restrictions on rare earths exports and examines how Brazil could seize the opportunity of its potential as a rare earth producer to strengthen its position on the international system. It is concluded that the WTO dispute was only the first chapter of a history of international tensions that are to come on the international stage.

Keywords: Rare Earth; WTO; China; Brazil

A recente oferta apertada de energia, alimentos e muitas matérias-primas também provocou uma preocupação mais geral - que possamos passar de uma era de abundantes suprimentos para uma de constante escassez. [Governo dos Estados Unidos/Administração Nixon, 1974. Critical Imported Materials: Study of Ad Hoc Group Established by NSSM 197/CIEPSM 33 (BUIJS; SIEVERS, 2011)]. ${ }^{3}$

O Oriente Médio tem seu petróleo, a China tem terras raras: os depósitos de terras raras da China representam $80 \%$ das reservas globais identificadas, podese comparar o status dessas reservas com o do petróleo no Oriente Médio: é de importância estratégica extremamente importante; devemos ter certeza de lidar com a questão das terras raras corretamente e aproveitar ao máximo a vantagem do nosso país em recursos de terras raras [Discurso de Deng Xiaoping em 1992 (KIGGINS, 2015)]. ${ }^{4}$

\section{Introdução}

As variações de oferta e as dificuldades de acesso a determinados produtos estratégicos para a economia mundial podem provocar mudanças na geopolítica internacional. Os dois choques do petróleo ocorridos na década de 1970 são, talvez, os exemplos mais conhecidos de como a reconfiguração do poder pode ser redesenhada em função de quem detém determinado recurso natural estratégico.

3 The recent tight supply situation for energy, food and many raw materials has also prompted a more general concern-that we may be passing from an era of abundant supplies into one of constant shortages. [US Government (Nixon Administration, 1974). Critical Imported Materials: Study of Ad Hoc Group Established by NSSM 197/CIEPSM 33 (BUIJS; SIEVERS, 2011)].

4 The Middle East has its oil, China has rare earth: China's rare earth deposits account for 80 percent of identified global reserves, you can compare the status of these reserves to that of oil in the Middle East: it is of extremely important strategic significance; we must be sure to handle the rare earth issue properly and make the fullest use of our country's advantage in rare earth resources. [Discurso de Deng Xiaoping em 1992 (KIGGINS, 2015)]. 
Na primeira década do século XXI, o mercado internacional de matériasprimas, commodities e minerais experimentou um aumento da demanda mundial em virtude da aceleração do crescimento econômico mundial, em especial dos países em desenvolvimento de renda média, especialmente a China, a Índia e, em menor medida, o Brasil. Após a crise de 2008, o crescimento da economia mundial foi reduzido, mas não comprimiu na mesma proporção a demanda por matérias-primas, a exemplo das terras raras.

Os recursos naturais estão distribuídos de forma desigual ao redor da Terra, assim como a tecnologia disponível e a capacidade de investimento não são iguais em qualquer parte do globo. Alguns recursos são encontrados em poucas regiões do mundo e a sua exploração e exportação dependem de poucos países. Quando metade ou mais da produção mundial de determinada matéria-prima está concentrada num único país, os países importadores tornam-se dependentes desse produtor, que passa a deter grande poder de influência sobre os preços e sobre as quantidades comercializadas mundialmente. Essa foi a situação que ocorreu entre o fim da década de 1990 e a década de 2000, com relação à produção e exportação de terras raras, tendo a China o monopólio mundial desse mercado.

Este artigo busca fazer uma primeira reflexão acerca da tensão internacional pelo acesso às terras raras, que surgiu a partir da segunda década dos anos 2000. A primeira parte faz um rápido apanhado acerca das metodologias e das variáveis utilizadas para estabelecer o grau de criticidade de uma matéria-prima. A segunda parte situa o leitor acerca da importância das terras raras para as indústrias civil e militar. Em seguida, expõe o panorama do mercado internacional de terras raras, identificando os países detentores das principais reservas desses minerais. Procura demonstrar a preocupação dos principais países importadores de terras raras e como a tensão gerada por garantir o acesso às terras raras entre os Estados Unidos, a União Europeia e o Japão de um lado, e a China de outro, chegou à Organização Mundial do Comércio (OMC). Ao final, o artigo aponta as principais medidas tomadas pela comunidade acadêmica e pelo governo brasileiro e apresenta as considerações finais.

Os riscos ligados às dificuldades de acesso a determinados recursos estratégicos, na maioria das vezes, estão ligados a situações como a instabilidade política nos países exportadores, a nacionalização de minas e de empresas mineradoras, questões ligadas à proteção ambiental, à adoção de política de desenvolvimento nacional que busque priorizar a utilização das matérias-primas nos países produtores ou à ocorrência de desastres ambientais. Em contraponto a situações dessa natureza, 
os países importadores podem levar a cabo políticas de armazenamento de longo prazo, estabelecer contratos de compra e venda de longo prazo, desenvolver pesquisas para obter maiores taxas de reciclagem e/ou de substituição de matériasprimas ou ainda buscar aumentar a eficiência produtiva.

Alguns trabalhos de pesquisa têm buscado avaliar a possibilidade de redução do fluxo de suprimento de determinadas matérias-primas, bem como o impacto econômico que choques de oferta podem provocar (MAYER; GLEICH, 2015; NASSAR et al., 2012; BUIJS; SIEVERS, 2011; BUIJS; SIEVERS; TERCERO ESPINOZA; 2012; GRAEDEL et al., 2012; HATCH, 2011). O conceito de criticidade de matéria-prima apareceu pela primeira vez em 1939 (MAYER; GLEICH, 2015), no documento Material Stock Piling Act, cuja intenção era regular o acesso a certas matériasprimas relevantes para a indústria militar.

De acordo com Buijs e Sievers (2011), uma avaliação não adequada dos riscos pode resultar numa reação desproporcional. Segundo Buijs, Sievers e Tercero Espinoza (2012), o termo "matéria-prima crítica" significa que aquela matériaprima combina duas características: grande importância econômica e risco de quebra no seu fornecimento. Está claro que estabelecer a criticidade de uma matéria-prima é um conceito relativo, pois traz consigo certa imprecisão, já que não parecem ser facilmente mensuráveis a importância econômica e o risco de quebra de fornecimento. Tampouco há um consenso acerca de quais indicadores poderiam ser utilizados satisfatoriamente. O grau de dependência de um país em relação a fornecedores estrangeiros pode ser um dos indicadores aceitáveis. Hatch (2011) sugere como um desses indicadores a combinação de projeção de oferta e de demanda. Não é simples a mensuração dessas variáveis, ainda mais porque o contexto de cada mercado pode mudar ao longo do tempo, variando em função de quais países são exportadores e importadores. A inovação tecnológica tanto pode prescindir de determinada matéria-prima antes utilizada, contribuindo para a redução de sua demanda, como pode provocar o aumento da procura por determinada matéria-prima e assim suscitar um rápido aumento nos seus preços internacionais, principalmente quando se trata de mercados cuja oferta é inelástica e responde lentamente aos estímulos de demanda. Fatores como o curto, o médio e o longo prazo também são fatores importantes para uma melhor avaliação acerca dos ciclos de oferta. Todos esses fatores precisam ser levados em conta ao se tentar avaliar o nível de vulnerabilidade de países ou de empresas que dependem da importação de certo produto. O Gráfico 1 traz um esquema utilizado pela Comissão Europeia (EUROPEAN COMMISSION, 2010) que busca sistematizar uma forma 
de classificar uma matéria-prima como crítica. De acordo com esse parâmetro, uma matéria-prima só poderia ser assim classificada se estivesse no quadrante superior direito, ou seja, se a matéria-prima apresentar concomitantemente alta "Importância Econômica" e "Risco de Quebra de Oferta".

Gráfico 1: Representação do grau de "criticidade" de um bem a partir dos indicadores "Importância Econômica" e "Risco de Quebra de Oferta" (incluídas as taxas de substituição e de reciclagem)

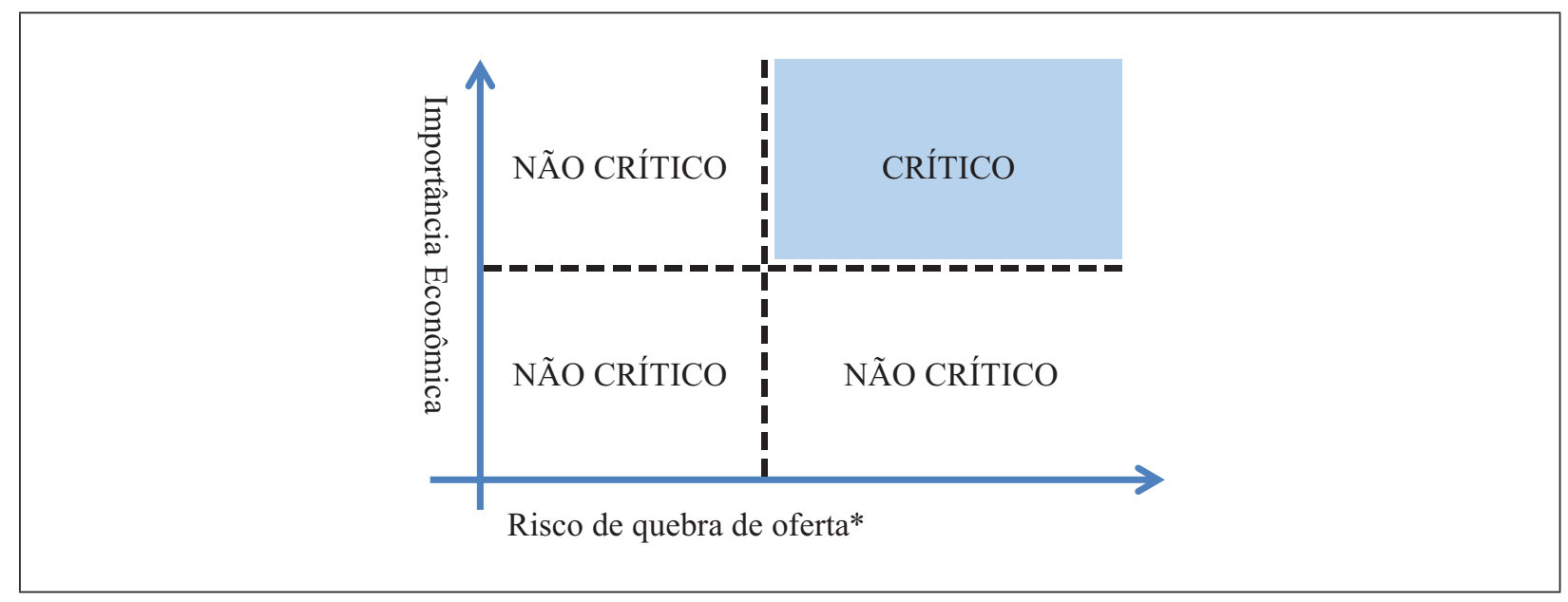

* Inclui taxa de substituição e de reciclagem.

Fonte: BUIJS; SIEVERS, 2011.

O tema das restrições às exportações nunca ganhou importância nas rodadas do Acordo Geral sobre Tarifas e Comércio (GATT) nem nas da OMC. Tradicionalmente, os temas das rodadas sempre estavam ligados ao protecionismo, às barreiras às importações, aos subsídios, ao dumping, ao comércio desleal e aos direitos de propriedade intelectual. Ou seja, o embate no GATT e na OMC sempre se dava no sentido de que países sentiam-se prejudicados por não poderem exportar mais ou por considerarem-se vítimas de uma concorrência desleal que punha em risco algum setor econômico. Daí os temas ligados à defesa comercial, aos subsídios, às normas de salvaguardas e às medidas compensatórias tomarem grande parte das discussões no âmbito da OMC. Portanto, o contencioso na OMC que teve início em 2012, sobre as restrições às exportações de terras raras chinesas, pode ser considerado paradigmático porque inverte a lógica habitual das disputas: agora o país importador exige que o país exportador lhe venda.

Ao se observar o número das disputas registradas pela OMC no seu portal oficial (WORLD TRADE ORGANIZATION, [sem data]), desde a sua fundação em janeiro de 1995 até 8 de março de 2017, constata-se que houve 524 disputas. 
A grande maioria delas dizia respeito à concorrência desleal e a alguma forma de protecionismo. Dessas 524 demandas, apenas 9 diziam respeito a restrições à exportação ${ }^{5}$. Dados da Organização para Cooperação e o Desenvolvimento Econômico (OCDE) demonstram que, a partir do início da década de 2000, o número de países que tomaram medidas para restringir suas exportações aumentou. Entre 1997 e 2002, a OMC registrou 39 casos (entre os 100 países membros), enquanto que, entre 2003 e 2009, foram registrados 65 (entre os 128 países membros) (KIM, 2010). Os produtos mais afetados pelas restrições foram minerais, metais, pedras preciosas, produtos agrícolas, florestais e de pesca. A maioria dos países que faz uso dessas restrições são países em desenvolvimento. Diferentes razões levam os países a adotarem restrições às exportações. As mais frequentes são as ligadas à segurança estratégica (para garantir o acesso a determinado insumo), segurança nacional e/ou internacional (restrições de venda de armas e produtos correlatos a determinados países), ao controle da inflação, ao aumento da arrecadação tributária, à segurança alimentar e à proteção ambiental. Talvez o caso mais conhecido de proibição de exportação com fins estratégicos seja o dos Estados Unidos que, em 1973, em plena crise do choque do petróleo, proibiram a exportação de petróleo.

\section{Terras Raras, minerais singulares}

As terras raras são um conjunto de 17 elementos químicos da tabela periódica compreendidos entre os números atômicos 57 e 71 (Lantânio -La-, Cério -Ce-, Praseodímio -Pr-, Neodímio -Nd-, Promécio -Pm-, Samário -Sm-, Európio -Eu-, Gadolínio -Gd-, Térbio -Tb-, Disprósio -Dy-, Hólmio -Ho-, Érbio -Er-, Túlio Tm-, Itérbio -Yb- e Lutécio -Lu), além dos números atômicos 21, Escândio -Sc-, e o 39, o Ítrio -Y. A sua localização na Tabela Periódica dos Elementos aparece em destaque na Figura 1.

5 As duas primeiras foram interpostas pela União Europeia por restrições à exportação de couro contra o Paquistão, em 1997, (DS 107, 07/11/1997), e contra a Índia, em 1998 (DS 120, 11/03/1998). A partir de 2009, todas as demandas foram contra a China. Três casos por restrições à exportação de algumas matérias-primas, reclamadas pelos Estados Unidos e pela União Europeia (DS 394 e DS 395, ambos em 23/06/2009) e pelo México (DS 398, 21/08/2009). Em 2012, os Estados Unidos, o Japão e a União Europeia denunciaram a China por restrições à exportação de terras raras (DS 431, DS 432 e DS 433, 13/03/2012). Finalmente, em 2016, a União Europeia denunciou a China por restrição à exportação de algumas matérias-primas (DS 509, 23/11/2016). 
Figura 1: Tabela Periódica: terras raras

\begin{tabular}{|c|c|c|c|c|c|c|c|c|c|c|c|c|c|}
\hline \multicolumn{13}{|l|}{$\mathrm{H}$} & \multirow{2}{*}{$\frac{\mathrm{He}}{\mathrm{Ne}}$} \\
\hline Li & $\mathrm{Be}$ & & & & & & & & & $\mathrm{N}$ & 0 & $F$ & \\
\hline $\mathrm{Na}$ & $\mathrm{Mg}$ & & & & & & & & & $P$ & $S$ & $\mathrm{Cl}$ & $\mathrm{Ar}$ \\
\hline K & $\mathrm{Ca}$ & Sc & Ti & V & $\mathrm{Cr}$ & $\mathrm{Mn}$ & $\mathrm{Fe}$ & $\mathrm{Cc}$ & $N$ & As & $\mathrm{Se}$ & $\mathrm{Br}$ & $\mathrm{Kr}$ \\
\hline $\mathrm{Rb}$ & $\mathrm{Sr}$ & Y & $\mathrm{Zr}$ & $\mathrm{Nb}$ & Mo & Tc & Ru & $\mathrm{Rr}$ & $P$ & $\mathrm{Sb}$ & Te & 1 & Xe \\
\hline Cs & $\mathrm{Ba}$ & La-Lu & $\mathrm{Hf}$ & $\mathrm{Ta}$ & W & $\operatorname{Re}$ & Os & Ir & P & $\mathrm{Bi}$ & Po & At & $\mathrm{Rn}$ \\
\hline $\mathrm{Fr}$ & $\mathrm{Ra}$ & Ac-Lr & $\mathrm{Rf}$ & $\mathrm{Db}$ & $\mathrm{Sg}$ & $\mathrm{Bh}$ & $\mathrm{Hs}$ & $M$ & D & Uup & LV & Uus & Uuo \\
\hline & & Lanta & ídeo & & & & & & & & & & \\
\hline & & La & $\mathrm{Ce}$ & $\mathrm{Pr}$ & $\mathrm{Nd}$ & $\mathrm{Pm}$ & $\mathrm{Sm}$ & Ec & G & $\mathrm{Tm}$ & $\mathrm{Yb}$ & Lu & \\
\hline
\end{tabular}

Fonte: elaboração própria com base em TABELA, 2017.

Apesar do nome, esses 17 elementos químicos nem são terras, nem são raros, quando comparados a outros elementos químicos mais escassos na natureza, a exemplo da prata. O seu nome deriva da dificuldade tecnológica e do alto custo para extraí-los, separá-los e purificá-los para o uso em escala industrial. Normalmente, as terras raras são divididas em dois grupos: leves e pesadas, e sua utilização mais detalhada está descrita no Quadro 1.

As terras raras estão presentes em mais de duzentas e cinquenta substâncias minerais, mas só em algumas dessas substâncias ocorrem terras raras em concentração suficiente para justificar seu aproveitamento (CÂMARA DOS DEPUTADOS, 2014). As principais substâncias minerais das quais se pode extrair terras raras em quantidades industriais são monazita, bastnaesita, xenotímio e certas argilas. Essas argilas, exploradas apenas na China, e o xenotímio são as principais fontes de terras raras pesadas. Já a monazita e a bastnaesita são importantes fontes de terras raras leves (CÂMARA DOS DEPUTADOS, 2014).

Segundo Martins e Isolani (2005), a totalidade das terras raras só passou a ser conhecida no início do século XX. O uso industrial teve início com a utilização na fabricação de camisas para lampiões. A partir de então, o uso industrial das terras raras tem aumentado com o descobrimento de novos usos, a exemplo das telas de LCD, das baterias de equipamentos eletrônicos e do crescimento das energias renováveis. Prevê-se que a demanda mundial desse tipo de produto aumente com o desenvolvimento de novas tecnologias. Apesar de esses minerais 
representarem uma percentagem muito baixa da composição do produto final, sua utilização é essencial para o desenvolvimento de produtos tecnologicamente sofisticados e, portanto, as terras raras tornaram-se uma matéria-prima estratégica no desenvolvimento de produtos para as áreas militar e civil.

A demanda por esse tipo de produto se explica pelo aumento de sua aplicação em novos processos de produção industrial e por possuir propriedades químicas magnéticas e fluorescentes únicas. O prolongamento do tempo de vida útil das baterias, bem como a capacidade de torná-las menores e mais leves, dependem essencialmente da utilização das terras raras. A indústria das energias renováveis, a exemplo da energia eólica, depende da aplicação das terras raras, especialmente no que diz respeito ao acúmulo e à conservação da energia gerada. Esses metais são, portanto, utilizados na produção de energias renováveis, no processamento de petróleo, em aplicações metalúrgicas, na fabricação de laser e na fabricação de produtos de tecnologia de ponta como: catalisadores, iluminação de displays, telas de computadores, telas de plasma, LED's, tablets, smartphones, geradores eólicos, veículos híbridos, fibras óticas, motores de aviões, componentes de cápsulas espaciais e satélites, baterias recarregáveis, ímãs de alto rendimento, supercondutores, luminóforos, equipamentos de comunicação à distância, memórias de computadores e de telefones celulares.

No que se refere a equipamento militar, as ligas metálicas com terras raras são fundamentais para o funcionamento de diversos armamentos e equipamentos. As munições de precisão perdem a sua eficiência de seu trajeto rumo ao alvo na falta de terras raras, ou seja, há uma perda importante na capacidade de precisão e, consequentemente, poderia haver um aumento no índice de baixas civis (KIGGINS, 2015). O Samário (Sm) e o Neodímio (Nd) são as terras raras mais utilizadas em equipamentos militares. São essenciais para a produção de sistemas de radar, ímãs que suportam altas temperaturas, utilizados em mísseis teleguiados, “bombas de precisão”, turbinas eólicas e caças (HUMPHRIES, 2012). Talvez seja por esse aspecto, o da possibilidade de redução do suprimento de terras raras para viabilizar a eficiência dos equipamentos militares, que os países tenham a percepção de insegurança, principalmente aqueles que possuem os equipamentos militares tecnologicamente mais avançados.

As terras raras possuem ainda uma vasta aplicação biológica, como em sondas espectroscópicas no estudo de biomoléculas, traçadores biológicos para acompanhar o caminho percorrido pelos medicamentos em pessoas e em animais; marcadores em imunologia, agentes de contraste em diagnóstico não invasivo de 
patologias em tecidos por imagem de ressonância magnética nuclear (MARTINS; ISOLANI, 2005).

No Quadro 1, pode-se observar um resumo das principais utilizações industriais das terras raras.

Quadro 1: Terras raras e suas aplicações.

\begin{tabular}{|l|c|l|}
\hline \multicolumn{1}{|c|}{ Terra Rara } & Tipo & \\
\hline Escândio & Leve & Aeronáutica, espacial, óptica \\
\hline Lantânio & Leve & Supercondutores, laser, motores híbridos, ligas metálicas, baterias \\
\hline Cério & Leve & $\begin{array}{l}\text { Catalizadores para carro e para refino de petróleo, ligas metálicas, telas } \\
\text { de cristal líquido, óptica }\end{array}$ \\
\hline Praseodímio & Leve & Ímãs, aeronáutica, espacial \\
\hline Neodímio & Leve & $\begin{array}{l}\text { Ímãs de alta resistência, catalizadores para carro e para refino de petróleo, } \\
\text { discos rígidos para laptops, fones de ouvido, ímãs, motores híbridos }\end{array}$ \\
\hline Promécio & Leve & Iluminação sem elevação de temperatura, espacial, radiologia \\
\hline Samário & Leve & Supercondutores, óptica, ímãs, eletrônica \\
\hline Európio & Leve & $\begin{array}{l}\text { Supercondutores, nuclear, tubos fluorescentes, cor vermelha para } \\
\text { televisão e telas de computadores }\end{array}$ \\
\hline Ítrio & Pesado & $\begin{array}{l}\text { Miras a laser, supercondutores, cor vermelha de lâmpadas fluorescentes, } \\
\text { cerâmicas agentes de ligas metálicas }\end{array}$ \\
\hline Gadolínio & Pesado & $\begin{array}{l}\text { Nuclear, radares, supercondutores, iluminação fosforescente, sistema de } \\
\text { guia de mísseis, ímãs }\end{array}$ \\
\hline Térbio & Pesado & Laser, iluminação fosforescente, lâmpadas de baixo consumo, ímãs \\
\hline Disprósio & Pesado & Nuclear, aeronáutica, ímãs de alta resistência, motores híbridos \\
\hline Hólmio & Pesado & $\begin{array}{l}\text { Laser, supercondutores, magnetismo, óculos especiais, corantes de vidro } \\
\text { laser }\end{array}$ \\
\hline Érbio & Pesado & Nuclear, metalurgia, energia fotovoltaica, fibra ótica \\
\hline Túlio & Pesado & Bateria nuclear, supercondutores, laser, radiologia \\
\hline Lutécio & Supercondutores, metalurgia inoxidável, ligas de aço \\
\hline
\end{tabular}

Fonte: elaboração própria a partir de dados de WEBER, 2012 e CÂMARA DOS DEPUTADOS, 2014.

Espera-se que a demanda por baterias recarregáveis de alto rendimento aumente em razão da evolução dos equipamentos elétricos e eletrônicos, seja para uso civil ou militar. Segundo o relatório da Comissão Europeia (EUROPEAN COMMISSION, 2010), a demanda de matérias-primas para a fabricação desse tipo de bateria deve crescer a uma taxa de $5 \%$ entre 2010 e 2020, o que, necessariamente, significa um aumento da demanda de terras raras. 


\section{Mercado mundial de terras raras}

Entre a década de 1980 e 2010, o mercado mundial de terras raras experimentou uma grande mudança. No final da década de 1980, a China vendia menos da metade das terras raras comercializadas no mundo. A partir de então, a sua fatia de mercado cresceu paulatinamente e, em duas décadas, a China passou a ter o monopólio desse mercado. Com custos de produção mais baixos do que os de outros países produtores, possivelmente por dispor de um custo de mão de obra mais barato e de uma legislação ambiental mais laxa, não foi difícil para a China tornar-se líder mundial do mercado de terras raras. Assim como o Brasil, os EUA deixaram de produzir terras raras entre as décadas de 1980 e 1990, e passaram a comprá-las da China, aparentemente pelo fato de ser mais barato importá-las do que produzi-las internamente. De acordo com Buijs, Sievers e Tercero Espinoza (2012, p. 204), “a principal razão para o fechamento da mina de Mountain Pass, na Califórnia, nos Estados Unidos, que nos anos 1970 representava $70 \%$ da oferta global de terras raras, foi que não pôde competir com os preços baixos da oferta chinesa" 6 . Em 2014, a China respondia por $95 \%$ das terras raras comercializadas no mundo (SOUSA FILHO; SERRA, 2014). Portanto, a China tinha e ainda tem o monopólio da venda desses minerais estratégicos.

Autores como Kiggins (2015) consideram que a China tem o objetivo de criar uma cadeia produtiva de terras raras, como parte de sua busca por manter o seu desenvolvimento econômico e, ao mesmo tempo, modernizar o seu aparato militar. Ainda segundo Kiggins (2015), a estratégia chinesa para o uso das terras raras, passa pelo desenvolvimento de seu setor industrial, em parte assentado no uso das terras raras para implementar novas tecnologias nas áreas de transporte, de comunicação e de defesa militar, e, finalmente, pelo exercício de sua influência sobre países dependentes da importação das terras raras.

Em 2010, o governo chinês tomou a iniciativa de racionalizar o setor ligado à produção de terras raras, reduzindo o número de empresas para ter um maior controle sobre a produção. Tal medida lhe permitiu aumentar a eficiência e a produtividade, bem como ter um maior controle sobre o impacto ambiental provocado pela exploração de terras raras (ZHANG, 2013 apud KIGGINS, 2015).

\footnotetext{
6 The main reason for the closure of the Mountain Pass mine in California in the United States, which in the 1970s provided 70 per cent of the global supply of rare earths, was that it could not compete anymore against such cheap Chinese supplies.
} 
A iniciativa de restringir as exportações de terras raras através da imposição de cotas de exportação, obrigação de obtenção de licenças especiais para exportação de terras raras, cobrança de impostos adicionais aos exportadores, entre outras iniciativas, foi um dos meios para atingir o seu objetivo. O conjunto dessas medidas provocou um aumento dos preços das terras raras exportadas pela China e, concomitantemente, uma diferença significativa entre o preço das terras raras vendidas dentro do mercado chinês e seu preço no mercado internacional. Segundo Kerinek e Kim (2010), os preços internacionais das terras raras chegaram a estar cerca de $20 \%$ a $40 \%$ acima dos preços praticados dentro do mercado chinês.

Por ser uma grande fornecedora desse produto, essas restrições, por um lado, causaram aumento dos preços internacionais e, por outro, "desvirtuaram a livre concorrência” ao obrigar as empresas localizadas fora da China a comprar terras raras por preços superiores aos comprados por empresas concorrentes localizadas na China. Essas medidas foram interpretadas por outros países como "subsídios artificiais" que beneficiavam as empresas chinesas.

Os preços internacionais das terras raras mantiveram-se relativamente estáveis durante a primeira metade da década de 2000. As medidas tomadas pelo governo chinês para restringir as exportações de terras raras, combinadas com a demanda crescente desses minerais, provocaram um rápido crescimento dos preços das terras raras no mercado internacional.

Quadro 2: Preços de alguns óxidos de terras raras - 2002 a 2013 (US\$/quilograma)

\begin{tabular}{|c|c|c|c|c|c|c|c|c|}
\hline \multirow{2}{*}{ Ano } & \multicolumn{7}{|c|}{ Te r r a s $\mathbf{R}$ a r a s } \\
\cline { 2 - 9 } & La & Ce & Nd & Pr & Sm & Dy & Eu & Tb \\
\hline $\mathbf{2 0 0 2}$ & 2,30 & 2,30 & 4,40 & 3,90 & 3,00 & 20,00 & 240,00 & 170,00 \\
$\mathbf{2 0 0 3}$ & 1,50 & 1,70 & 4,40 & 4,20 & 2,70 & 14,60 & 235,40 & 170,00 \\
$\mathbf{2 0 0 4}$ & 1,60 & 1,60 & 5,80 & 8,00 & 2,70 & 30,30 & 310,50 & 300,00 \\
$\mathbf{2 0 0 5}$ & 1,50 & 1,40 & 6,10 & 7,60 & 2,60 & 36,40 & 286,20 & 300,00 \\
$\mathbf{2 0 0 6}$ & 2,20 & 1,70 & 11,10 & 10,70 & 2,40 & 70,40 & 240,00 & 434,00 \\
$\mathbf{2 0 0 7}$ & 3,40 & 3,00 & 30,20 & 29,10 & 3,60 & 89,10 & 323,90 & 590,40 \\
$\mathbf{2 0 0 8}$ & 8,70 & 4,60 & 31,90 & 29,50 & 5,20 & 118,50 & 481,90 & 720,80 \\
$\mathbf{2 0 0 9}$ & 4,90 & 3,90 & 19,10 & 18,00 & 3,40 & 115,70 & 492,90 & 361,70 \\
$\mathbf{2 0 1 0}$ & 4,23 & 3,55 & 29,28 & 27,60 & 2,47 & 166,48 & 410,42 & 388,80 \\
$\mathbf{2 0 1 1}$ & 16,26 & 19,58 & 132,06 & 104,60 & 11,85 & 994,33 & $2.025,00$ & $1.596,82$ \\
$\mathbf{2 0 1 2}$ & 11,46 & 11,76 & 74,72 & 70,51 & 10,44 & 620,73 & $1.178,34$ & 949,04 \\
$\mathbf{2 0 1 3}$ & 5,40 & 5,40 & 51,20 & 73,10 & 5,60 & 313,60 & 741,00 & 584,30 \\
\hline
\end{tabular}

Fonte: Câmara dos Deputados, 2014. 
O preço das terras raras apresentou uma ligeira variação positiva entre 2002 e 2005. Entre 2005 e 2011, houve um rápido aumento dos preços até atingir o ápice em 2011. O Quadro 2 mostra o preço de alguns óxidos de terras raras entre 2002 e 2013. Entre 2002 e 2011, o preço do Disprósio (Dy) foi multiplicado por 49, o do Neodímio (Nd) foi multiplicado por 30 e o do Praseodímio (Pr) foi multiplicado por 26. A menor variação foi a do Samário $(\mathrm{Sm})$, cujo preço foi multiplicado por praticamente 4 .

Esse aumento dos preços das terras raras se deu em função de dois fatores combinados, um pelo lado da demanda e outro pelo lado da oferta: o aumento da demanda mundial e as restrições à exportação adotadas pelo governo chinês. Apesar de as terras raras terem valor unitário relativamente alto, o impacto no preço final dos produtos foi insignificante por causa da diminuta concentração desses minerais presente nos produtos acabados. A partir de 2012, quando a China iniciou o relaxamento nas medidas restritivas à exportação, os preços internacionais começaram a baixar.

Com a tecnologia disponível atualmente, é possível realizar a reciclagem de terras raras, mas a um custo que não é viável economicamente. No que se refere à substituição desses minérios por sucedâneos, todos apresentam um resultado aquém daquele que se obtém com as terras raras, o que torna os países importadores desses minerais dependentes dos produtores (EUROPEAN COMMISSION, 2010). Alguns países, como Japão, Alemanha e Estados Unidos, têm feito investimentos em pesquisas para descobrir substitutos das terras raras.

Quadro 3: Reservas globais de terras raras - 2010 (em \%).

\begin{tabular}{|l|c|}
\hline \multicolumn{1}{|c|}{ País } & \% do total \\
\hline Brasil & 37,01 \\
China & 25,33 \\
Comunidade dos Estados Independentes - CEI & 13,37 \\
Vietnã & 10,42 \\
Groelândia & 3,44 \\
Canadá & 2,90 \\
Austrália & 2,34 \\
Índia & 2,18 \\
Estados Unidos & 1,06 \\
África do Sul & 0,88 \\
Quênia & 0,68 \\
Quirguistão & 0,20 \\
Turquia & 0,09 \\
Malawi & 0,08 \\
\hline
\end{tabular}

Fonte: USGS apud CHEN, 2011, p. 3. 
O Quadro 3 apresenta os dados sobre as maiores reservas globais de terras raras. De acordo com o U.S. Geological Survey (USGS), as reservas seriam aqueles recursos de terras raras prontos para o uso industrial. O Brasil aparece em primeiro lugar, com 37,01\%, seguido da China, com 25,33\%, da Comunidade dos Estados Independentes (CEI), com 13,37\%, e, em quarto lugar, do Vietnã, com 10,42\% . Portanto, segundo esses dados, podemos intuir que o Brasil possui um enorme potencial para desenvolver uma cadeia produtiva de terras raras.

\section{Dependência dos principais importadores: EUA, Japão e União Europeia}

Países industrializados, em especial a União Europeia, os Estados Unidos e o Japão, têm-se mostrado preocupados com a possibilidade de não ter acesso a certas matérias-primas, incluídas as terras raras, cuja oferta, caso seja reduzida, pode ter importantes implicações para o funcionamento de suas economias.

O aumento da competição propiciado pela globalização tem incentivado alguns países a perseguir estratégias de desenvolvimento industrial e comercial através de medidas que reservam seus recursos para uso próprio. Nesse caso, as restrições às exportações buscam assegurar o fornecimento de insumos mais baratos à indústria nacional.

A Comissão Europeia divulgou um relatório, em fevereiro de 2011, intitulado Tackling the challenges in commodity markets and on raw materials, no qual demonstrou a sua preocupação com o suprimento de matérias-primas no mercado mundial (EUROPEAN COMMISSION, 2011). O relatório lista 14 matérias-primas, inclusive as terras raras, cuja oferta mundial é considerada crítica pela União Europeia. Em maio de 2014, a Comissão Europeia publicou outro relatório intitulado Sobre a revisão da lista de matérias-primas essenciais para a UE e a implementação da Iniciativa Matérias-Primas, que atualiza o relatório de 2011. Nesse segundo relatório, as terras raras continuam a fazer parte da lista de matérias-primas consideradas "essenciais porque os riscos de escassez do aprovisionamento e a sua repercussão na economia são maiores do que os das outras matérias-primas” (COMISSÃO EUROPEIA, 2014).

O critério utilizado pela Comissão Europeia para considerar a oferta mundial crítica depende de duas variáreis: 1) o risco de haver redução do suprimento, que leva em conta a estabilidade político-econômica do país produtor, o nível de 
concentração da produção, a possibilidade de substituição do bem e a taxa de reciclagem e reaproveitamento; e 2) a importância econômica do bem. O termo "crítico" é utilizado pela Comissão Europeia para referir-se à possibilidade (ou ocorrência) de redução da oferta de um produto, redução essa capaz de provocar danos à economia de uma nação. É um entendimento vago o suficiente para deixarse incluir nessa definição os produtos que não têm grande peso econômico, mas possuem grande importância militar. Daí por que é importante um estudo mais detalhado sobre as preocupações dos países importadores, e sobre os motivos alegados pelos que restringem as exportações, para procurar identificar até que ponto estão em jogo interesses militares e econômicos.

Ao contrário do que acontece com várias commodities que são comercializadas na bolsa de valores, em particular na London Metals Exchange, o que torna o acesso a elas mais fácil, outras matérias-primas classificadas pela União Europeia como "críticas", como é o caso das terras raras, não o são. O mercado desses materiais é menos transparente e o seu volume comercializado é bem menor. Por não ser produtora de terras raras (apesar de a Suécia possuir jazidas de terras raras), a União Europeia preocupa-se com a adoção de medidas restritivas à exportação que países exportadores desses minerais podem tomar com o intuito de privilegiar suas empresas nacionais no acesso a esse tipo de produto. Ainda de acordo com o relatório da Comissão Europeia (EUROPEAN COMMISSION, 2011), a China tem armazenado terras raras para o seu próprio consumo e, em 2006, esse país introduziu um imposto de exportação cujo efeito foi o incremento do preço das terras raras em cerca de $31 \%$. Essas medidas poderiam criar distorções e incertezas nos mercados, afetando negativamente o fluxo de compra e venda desses produtos estratégicos.

De acordo com o relatório da Comissão Europeia (EUROPEAN COMMISSION, 2011), no médio prazo, a China passará a ter a necessidade de utilizar toda a sua produção de terras raras. Aliás, a China é deficitária na produção de matériasprimas em geral, situação que tem impelido o governo chinês a buscar garantir o seu suprimento de matérias-primas noutras partes do mundo através de uma política de investimentos no estrangeiro. No que se refere especificamente à política de investimentos para garantir o acesso às terras raras, merece destaque o esforço do governo chinês de estabelecer acordos de investimentos de mineração com a Groelândia, cujo potencial produtivo de terras raras é estimado em 40\% da produção chinesa (DEGEORGES, 2012). 
Em dezembro de 2013, a Comissão Europeia organizou em Bruxelas um seminário tripartite - US-Japan-EU Trilateral Workshop on Critical Raw Materials com os Estados Unidos e com o Japão para se trocarem informações e discutirem formas de garantir o acesso a matérias-primas não energéticas, entre as quais estavam as terras raras (EUROPEAN COMMISSION, 2013).

Espera-se que em função da redução da exportação chinesa de terras raras, outros países produtores invistam na produção. Países como Estados Unidos, Canadá, Índia, Austrália e Malawi trabalham para desenvolver a produção de terras raras (EUROPEAN COMMISSION, 2010). Mas o aumento da produção se dá em longo prazo, pois em certas ocasiões pode ser necessário até 10 anos entre o início da mineração até a produção final, além de que a produção de terras raras requer investimentos de grande monta. Portanto, pressões de demanda deverão acontecer nos próximos 5 ou 7 anos sem que a oferta possa atender a esse aumento. A situação pode ser ainda mais complicada para determinados tipos de terras raras, já que a rapidez da exploração varia em função do elemento químico em questão (EUROPEAN COMMISSION, 2011).

Em resumo, as barreiras que dificultam a entrada de novos produtores de terras raras no mercado mundial são o alto custo da tecnologia usada - e que é específica para cada tipo de terra rara; o alto custo de capital (mais de 30 mil dólares por tonelada); o fato de haver poucas empresas fora da China que detêm a tecnologia para a exploração; e o fato de o mercado estar dominado pela China, que possui custos relativos mais baixos de mineração (KORINEK; KIM, 2010).

A British Geological Survey publicou o Risk List 2015, que mostra o maior risco potencial de redução da oferta, que atinge os metais e elementos maciçamente usados nas indústrias de tecnologia e cuja produção e depósitos estão concentrados em poucos países. O grau de risco é medido numa escala que vai de 1 (risco mínimo) a 10 (máximo risco). São listados 41 elementos e os elementos de terras raras lideram a lista com nota 9,5 (RISK, 2015).

Algumas organizações de pesquisa especializadas, sediadas nos Estados Unidos, também publicaram relatórios chamando a atenção do governo estadunidense para o risco de estar na dependência do fornecimento da China no que diz respeito a um recurso estratégico como as terras raras. O Congressional Research Service publicou vários relatórios sobre o tema, entre os quais destacam-se o Rare Earth Elements in National Defense: Background, Oversight Issues, and Options for Congress (GRASSO, 2011), que alerta o Congresso estadunidense sobre a vulnerabilidade da indústria militar dos EUA ao depender das exportações chinesas de terras raras; e 
o China's Rare Earth Industry and Export Regime: Economic and Trade Implications for the United States (MORRISON; TANG, 2012), que amplia essa preocupação para vários setores da indústria civil. O think tank Council on Foreign Relations publicou, em 2014, um relatório intitulado Rare Earth Elements and National Security (GHOLZ, 2014). Em 2016, o National Science and Technology Council (NSTC), órgão vinculado à presidência dos Estados Unidos, publicou o relatório Assessment of Critical Minerals: Screening Methodology and Initial Application. Nesse relatório, as terras raras aparecem catalogadas como "critical minerals", categoria que, segundo esse mesmo relatório, significa matéria-prima cuja oferta mundial é vulnerável a interrupções e cuja falta poderia causar significativas consequências de ordem econômica e de segurança (NATIONAL SCIENCE AND TECHNOLOGY COUNCIL, 2016, p. IX).

Os Estados Unidos deixaram de produzir terras raras em 2003 e assim permaneceram até 2011. Após o pico dos preços ocorrido em 2011, voltaram a produzi-las em 2012, produção essa que perdurou até 2015. A partir de 2016, deixaram de produzi-las novamente e voltaram a importar $100 \%$ das terras raras das quais precisam. Em sua maioria, provenientes da China (UNITED STATES GEOLOGICAL SURVEY, 2017).

Os principais jornais de países dependentes da exportação de terras raras provenientes da China também refletiram tal preocupação. Algumas manchetes ilustram essa situação, como, por exemplo, "Escassez de terras raras, uma bomba-relógio" (DUNKLEY, 2011); "A China irrita o mundo enquanto a batalha por terras raras amplia-se” (WHITE; ROWLEY, 2012); "Recuperar as terras raras. Para não ser reféns da China” (TAGLIACARNE, 2012); “Terras raras: China reforça controle sobre metais de alta tecnologia" (SELTENE, 2012); "Os metais raros, o ouro do tecnológico século XXI” (MEXÍA, 2013); “As terras raras são o petróleo do século XXI" (FAUJAS, 2014).

\section{Reação dos principais importadores de terras raras: o embate chega à OMC}

Os Estados Unidos, a União Europeia e o México, em conjunto, fizeram uma solicitação formal à OMC em junho de 2009 para que fosse discutida a questão da restrição à exportação de terras raras. Em março de 2012, os EUA, a União Europeia e o Japão conseguiram abrir na OMC um painel contra a China por conta das restrições à exportação de terras raras. Nesse mesmo ano, a China abrandou 
algumas restrições à exportação de terras raras, o que fez com que os preços internacionais começassem a cair.

Os demandantes do painel alegaram que a política chinesa de contenção das exportações descumpriu os artigos VII, VIII, X e XI do GATT 1994, além dos parágrafos 2(A)2, 2(C)1, 5.1, 5.2, 7.2, 8.2 e 11.3 da Parte I do Protocolo de Acesso da China à OMC, bem como das obrigações firmadas no parágrafo 1.2, Parte I do mesmo Protocolo (DS 431, 2017). Alegaram ainda que o conjunto das medidas que restringiam a exportação de terras raras tinha o objetivo de coagir a transferência de indústrias para a China, causando assim perda de empregos e de capacidade produtiva noutros países. De acordo com tal entendimento, o aumento dos preços internacionais das terras raras desvirtuou a livre concorrência, ao impor às empresas estabelecidas fora da China a compra de terras raras a preços de $20 \%$ a $40 \%$ superiores aos praticados no mercado chinês. Essas medidas foram interpretadas pelos demandantes como "subsídios artificiais” que beneficiavam as empresas chinesas.

Do outro lado, a China argumentou que sua política de restrição à exportação de terras raras não foi direcionada a nenhum país em especial e que não houve nenhuma forma de protecionismo comercial, mas que "a política foi elaborada a partir da preocupação com a preservação do ambiente, do uso e do desenvolvimento sustentável dos recursos” (ORSI, 2012). A defesa da China buscou justificativa no princípio reconhecido pela OMC de que "todo país tem o direito de regular, limitar ou proibir a exploração de seus recursos naturais com objetivos de preservação do meio ambiente” (LIMA, 2011), já que o artigo XX do Acordo Geral sobre Tarifas Aduaneiras e Comércio de 1947 garante aos países o direito de tomar medidas comerciais restritivas para preservar recursos naturais.

O painel chegou ao fim em setembro de 2014, com a derrota da China. No entendimento da OMC, a China não poderia restringir a exportação de seus recursos naturais, no caso, as terras raras, para utilizá-las para a sua indústria nacional. Os juízes do painel entenderam que a China deveria cessar as medidas de restrição à exportação e continuar a vender as terras raras aos países importadores. Foi uma decisão paradigmática porque pôs em cheque a soberania dos países membros da OMC sobre seus recursos naturais. Abriu-se, portanto, uma importante discussão no âmbito da geopolítica mundial que interliga aspectos ambientais, econômicos, políticos, estratégicos, militares, de segurança e de desenvolvimento. Aí reside a importância desse tema que tem sido discutido no âmbito da OMC (MELO; DIAS, 2015). 
A derrota chinesa no painel da OMC e o afrouxamento das restrições à exportação impostas pela China reduziram os preços após o pico em 2011, mas não se espera que caiam mais, pois a tendência mundial é de aumento do consumo de terras raras num contexto de incertezas quanto à capacidade de a oferta mundial crescer na mesma proporção da demanda mundial.

\section{A posição do Brasil no mercado mundial de terras raras}

O Brasil se apresenta como um país que reúne grandes potencialidades como produtor de elementos de terras raras. De acordo com o relatório produzido pelo Senado Federal, intitulado "Terras raras: elementos estratégicos para o Brasil" (LIMA, 2012), o início do processo de desenvolvimento industrial na área de terras raras teve sua gênese no fim na primeira metade do século XX, no estado do Rio de Janeiro, quando a monazita começou a ser manufaturada e compostos fabricados a partir dela foram desenvolvidos pela Usina Santo Amaro, localizada no município de São Francisco de Itabapoana. Até 1915, o Brasil foi o maior produtor mundial de terras raras, quando perdeu a posição para a Índia.

Até os anos de 1990, produziam-se no Brasil matérias-primas originárias de terras raras, mas como o seu custo de produção era superior ao custo de produção chinês, a produção nacional tornou-se economicamente inviável (DEUTSCHE, 2013). De um modo geral, outras empresas de capital privado surgiram e foram encerradas nos anos de 1990 em estados como São Paulo, Rio de Janeiro e Minas Gerais, algumas das quais tendo suas atividades assumidas pela Indústrias Nucleares do Brasil S.A. (INB), existente até a atualidade.

Segundo Serra (2011), o total das reservas brasileiras de terras raras é de cerca de 50 mil toneladas, mas se forem consideradas as jazidas com menores teores (aproximadamente 10\%), como as de Catalão (GO) e de Araxá (MG), esse número chega ao valor estimado de quase cinco milhões de toneladas.

A comunidade acadêmica brasileira da área de química deu início, ainda que timidamente, a discussões mais ligadas a aspectos técnicos, a respeito do que envolve a pesquisa, a exploração e a comercialização das terras raras. O Primeiro Encontro sobre Terras Raras foi organizado pela Universidade Federal de Pernambuco (UFPE), na cidade de Recife (PE), em 1994. O segundo e o terceiro encontro foram realizados, em 1995 e em 2003, pela Universidade Estadual de São Paulo (UNESP), em Araraquara (SP). Em 2010, a Universidade Federal de Sergipe (UFS) organizou o quarto encontro na cidade de Aracaju (SE). Durante aquele 
encontro, foi elaborada uma carta ao então ministro de Ciência e Tecnologia, Sérgio Machado Resende, alertando sobre a necessidade da retomada da produção de terras raras no Brasil. Naquela carta, os signatários chamavam a atenção para o fato de ser o Brasil dependente das terras raras provenientes da China e ser, ao mesmo tempo, detentor de reservas capazes de suprir a demanda nacional. Em 2012, o Quinto Encontro sobre Terras Raras foi realizado em João Pessoa (PB), organizado pela Universidade Federal da Paraíba (UFPB). Finalmente, em 2014, a comunidade acadêmica da área de química organizou o Sexto Encontro na Universidade Federal de Pernambuco (UFPE), em Recife.

O governo brasileiro criou, em 2010, através da Portaria Interministerial n ${ }^{0}$ 614/2010, o Grupo de Trabalho Interministerial do Ministério de Minas e Energia e do Ministério de Ciência e Tecnologia de Minerais Estratégicos. Esse grupo de trabalho ressaltou a importância de se discutir uma política para minerais estratégicos para o Brasil. Ainda em 2010, foi elaborado o Plano Nacional de Mineração 2030 (PNM-2030), cujo objetivo é "nortear as políticas de médio e longo prazos que possam contribuir para que o setor mineral seja um alicerce para o desenvolvimento sustentável do País nos próximos 20 anos” (BRASIL, 2010, p. XIII). Em 2011, o Ministério da Ciência, Tecnologia e Inovação, através do Centro de Tecnologia Mineral (CETEM), organizou no Rio de Janeiro o I Seminário Brasileiro de Terras Raras. Essas ações do Poder Executivo brasileiro parecem indicar que o governo começa a ter uma noção da importância econômica e geopolítica das terras raras e, de forma mais abrangente, de outros metais estratégicos, como é o caso do nióbio. Dois anos depois, em 2013, o CETEM organizou o Segundo Seminário Brasileiro de Terras Raras e, finalmente, em 2015, o CETEM organizou o Terceiro Seminário Brasileiro de Terras Raras.

A organização dos três seminários pelo governo federal, através do Ministério de Minas e Energia e do Ministério de Ciência, Tecnologia e Inovação, demonstra que há, nos órgãos públicos especializados, quadros técnicos que reconhecem a importância estratégica das terras raras, ainda que as ações sejam tímidas. Outro fato digno de se mencionar foi a publicação do edital n 76/2013 MCTI/CNPq/ CT-Mineral, cujo objetivo era fomentar o desenvolvimento tecnológico com terras raras, o que parece indicar que o Poder Executivo começa a dar os primeiros passos para elaborar uma política nacional estratégica para a produção de terras raras no Brasil.

O Serviço Geológico do Brasil (CPRM), órgão vinculado ao Ministério de Minas e Energia, deu início, em janeiro de 2013, a um projeto para mapear as 
jazidas de elementos de terras raras em solo brasileiro. O Senado Federal teve uma iniciativa importante ao criar uma subcomissão especializada sobre terras raras no âmbito das discussões do Plano Nacional de Mineração 2030. Na Comissão de Ciência e Tecnologia do Senado Federal, em 2013, houve consenso no que se refere à necessidade de o Brasil voltar a pesquisar e desenvolver a indústria de tecnologia e bens advindos de terras raras. O já falecido senador Luis Henrique da Silveira (PMDB-SC), que foi relator da subcomissão de terras raras, defendeu que o Brasil deveria priorizar o setor e que a criação de um marco regulatório para mineração de terras raras seria estratégica para a segurança nacional. O plenário do Senado aprovou, em 2014, a criação do Programa de Apoio ao Desenvolvimento Tecnológico dos Minerais de Elementos Terras-Raras (PADETR).

Em 2013, o Ministério da Ciência, Tecnologia e Inovação (MCTI) anunciou o desembolso de $\mathrm{R} \$ 11$ milhões em pesquisa e desenvolvimento com terras raras. Desse montante, R $\$ 2$ milhões foram destinados ao Centro de Tecnologia Mineral (CETEM), que desenvolve o projeto Proterraras, iniciado em 2013, e que tem por finalidade contribuir para o domínio tecnológico da produção de óxidos de terras raras e de seus usos, como uma das etapas indispensáveis para a implantação e o desenvolvimento da cadeia produtiva de terras raras no Brasil.

\section{Conclusões}

Apesar da importância estratégica que os minerais terras raras representam tanto para o desenvolvimento da indústria civil quanto militar, o tema das terras raras ainda é pouco estudado na área das relações internacionais. Possivelmente, isso se deve à relativa estabilidade da oferta mundial desses minerais até essa segunda década do século XXI. Desde os anos de 1990, quando a China assumiu a liderança mundial na produção e exportação desses metais, não havia motivos para preocupação, pois a China exportava terras raras sem restrições e a preços competitivos e atrativos. Foi justamente por essa razão que outros países, como os Estados Unidos, o Brasil e a Austrália, outrora produtores de terras raras, baseados na racionalidade econômica, pararam de extrair esses minerais e tornaram-se dependentes da exportação chinesa.

No entanto, as restrições às exportações impostas pela China, a partir de meados dos anos 2000, encerraram a fase de estabilidade no suprimento de terras raras e deram início a um período de disputa comercial entre as grandes 
potências. Os Estados Unidos, a União Europeia e o Japão levaram o assunto à OMC, na tentativa de obrigar a China a cessar a sua política de restrição às exportações de terras raras. A derrota da China no diferendo da OMC sobre as terras raras levantou questões relevantes acerca da soberania e da independência dos países membros no que diz respeito ao uso de seus recursos naturais, haja vista que a China foi condenada pela OMC, em 2014, por restringir a exportação de seu recurso natural. Enquanto o suprimento global de terras raras se mantiver em níveis compatíveis com a demanda mundial, as tensões serão amainadas, no entanto, as previsões são de que antes de 2030 a própria China tornar-se-á importadora de terras raras. Tal situação futura poderá voltar a incitar conflito em torno do acesso a esses minérios.

As terras raras são matérias-primas estratégicas para o setor industrial, cuja falta pode ocasionar problemas relacionados à segurança, inclusive militar, ao desenvolvimento das chamadas energias renováveis e, de forma mais ampla, ao desenvolvimento econômico. Algumas questões ficam como interrogações para futuras pesquisas. As políticas industriais dos membros da OMC estarão sempre limitadas às regras dessa organização internacional? Será possível resolver o choque entre a autonomia nacional e as normas da OMC? Os constrangimentos no acesso às terras raras levarão a uma fase de cooperação internacional ou de acirramento de tensões? Usará a China a sua posição de principal produtor de terras raras para tentar pressionar países dependentes das terras raras por ela exportadas?

No que se refere ao Brasil, a comunidade acadêmica parece estar mais atenta à importância das terras raras para o desenvolvimento nacional do que o governo brasileiro. Foi essa comunidade que, em 2010, reunida durante o Quarto Encontro sobre Terras Raras, alertou o governo brasileiro, em carta enviada ao Ministério de Ciência, Tecnologia e Inovação, da necessidade da retomada da produção de terras raras. O Senado Federal tomou iniciativas importantes para discutir a retomada da produção de terras raras no Brasil. As medidas tomadas pelo poder executivo são ainda incipientes quando se pensa numa estratégia de longo prazo com o fim de desenvolver a cadeia produtiva de terras raras no Brasil. A julgar pelo que foi feito até agora pelo governo federal, os tomadores de decisão ainda não têm plena consciência da importância estratégica das terras raras nem no âmbito internacional, nem no potencial que esse recurso pode representar para o desenvolvimento nacional. 


\section{Referências}

BRASIL. Ministério de Minas e Energia. Plano Nacional de Mineração 2030 (PMN-2030). Brasília: MME, 2010.

BUIJS, B.; SIEVERS, H. Critical thinking about critical minerals: Assessing risks related to resource security. Polinares EU Policy on Natural Resources. The Hague: Clingendael International Energy Programme, 2011. Disponível em: http://www.clingendaelenergy. com/inc/upload/files/Critical_thinking_critical_minerals.pdf. Acesso em: 24 abr. 2017. BUIJS, B.; SIEVERS, H.; TERCERO ESPINOZA L. Limits to the critical raw materials approach. Waste and Resource Management, 165, November 2012, p. 201-208.

CÂMARA DOS DEPUTADOS. Centro de Estudos e Debates Estratégicos. Consultoria Legislativa. Minerais estratégicos e terras raras. Brasília: Edições Câmara, 2014.

CHEN, Zhanheng. Global rare earth resources and scenarios of future rare earth industry. Journal Of Rare Earths, v. 29, n. 1, Jan. 2011, p.1-6.

WORLD TRADE ORGANIZATION. Chronological list of disputes cases. Portal Oficial da OMC. Disponível em: https://www.wto.org/english/tratop_e/dispu_e/dispu_status_e. htm. Acesso em: 25 abr. 2017.

COMISSÃO EUROPEIA. Sobre a revisão da lista de matérias-primas essenciais para a UE e a implementação da Iniciativa Matérias-Primas. Comunicação da Comissão ao Parlamento Europeu, ao Conselho, ao Comité Económico e Social Europeu e ao Comité das Regiões. COM (2014) 297 final, 26/05/2014.

DEGEORGES, Damien. Terres rares: enjeu géopolitique du XXIe siècle - Chine, États Unis, Europe, Japon, Groenland. Paris: L’Harmattan, 2012.

DEUTSCHE Welle. Alheio a riscos, Brasil quer retomar extração de terras-raras. 2013. Disponível em: http://www.dw.de/alheio-a-riscos-brasil-quer-retomarextra \% C3 \% A7 \% C3 \% A3o-de-terras-raras/a-16896952. Acesso em: 21 mar. 2016.

DS 107 Pakistan - Export Measures Affecting Hides and Skins. 1997. World Trade Organization. Portal Oficial da OMC. Disponível em: https://www.wto.org/english/ tratop_e/dispu_e/cases_e/ds107_e.htm. Acesso em: 25 abr. 2017.

DS 120 - India - Measures Affecting Export of Certain Commodities. 1998. World Trade Organization. Portal Oficial da OMC. Disponível em: https://www.wto.org/english/ tratop_e/dispu_e/cases_e/ds120_e.htm. Acesso em: 25 abr. 2017.

DS 394 - China - Measures Related to the Exportation of Various Raw Materials. 2009. World Trade Organization. Portal Oficial da OMC. Disponível em: https://www. wto.org/english/tratop_e/dispu_e/cases_e/ds394_e.htm. Acesso em: 25 abr. 2017.

DS 395 - China - Measures Related to the Exportation of Various Raw Materials. 2009. World Trade Organization. Portal Oficial da OMC. Disponível em: https://www. wto.org/english/tratop_e/dispu_e/cases_e/ds395_e.htm. Acesso em: 25 abr. 2017. 
DS 398 - China - Measures Related to the Exportation of Various Raw Materials. 2009. World Trade Organization. Portal Oficial da OMC. Disponível em: https://www. wto.org/english/tratop_e/dispu_e/cases_e/ds398_e.htm. Acesso em: 25 abr. 2017.

DS 431 - China - Measures Related to the Exportation of Rare Earths, Tungsten and Molybdenum. World Trade Organization. Portal Oficial da OMC. Disponível em: https://www.wto.org/english/tratop_e/dispu_e/cases_e/ds431_e.htm. Acesso em: 25 abr. 2017.

DS 432 - China - Measures Related to the Exportation of Rare Earths, Tungsten and Molybdenum. 2012. World Trade Organization. Portal Oficial da OMC. Disponível em: https://www.wto.org/english/tratop_e/dispu_e/cases_e/ds432_e.htm. Acesso em: 25 abr. 2017.

DS 433 - China - Measures Related to the Exportation of Rare Earths, Tungsten and Molybdenum. 2012. World Trade Organization. Portal Oficial da OMC. Disponível em: https://www.wto.org/english/tratop_e/dispu_e/cases_e/ds433_e.htm. Acesso em: 25 abr. 2017.

DS 509 - China - Duties and other Measures concerning the Exportation of Certain Raw Materials. 2016. World Trade Organization. Portal Oficial da OMC. Disponível em: https://www.wto.org/english/tratop_e/dispu_e/cases_e/ds509_e.htm. Acesso em: 25 abr. 2017.

DUNKLEY, Jamie. Rare earth metal shortage a 'ticking time-bomb'. The Telegraph, 06/12/2011. Disponível em http://www.telegraph.co.uk/finance/newsbysector/ industry/mining/8938791/Rare-earth-metal-shortage-a-ticking-time-bomb.html. Acesso em: 21 mar. 2016.

EUROPEAN COMMISSION. Critical raw materials for the EU. Report of the Ad-hoc Working Group on defining critical raw materials. Version of 30 July 2010.

EUROPEAN COMMISSION. Tackling the challenges in commodity markets and on raw materials. Communication from the Commission to the European Parliament, the Council, the European Economic and Social Committee and the Committee of the Regions. COM (2011) 25 final. Brussels, 02/02/2011.

EUROPEAN COMMISSION. US-Japan-EU trilateral workshop on Critical Raw Materials. Workshop report. Brussels, 02/12/2013.

FAUJAS, Alain. Les terres rares sont le pétrole du XXe siècle. Le Monde, 16/06/2014. Disponível em: http://www.lemonde.fr/economie/article/2014/06/16/c-est-lemoment-d-investir-dans-les-terres-rares_4438932_3234.html. Acesso em: 21 mar. 2016. GHOLZ, Eugene. Rare Earth Elements and National Security. Energy Report. New York: Council on Foreign Relations, 2014.

GRAEDEL, T. E. et al. Methodology of metal criticality determination. Environmental Science and Technology, vol. 46, n. 2, 2012, p. 1063-1070. 
GRASSO, Valerie Bailey. Rare Earth Elements in National Defense: Background, Oversight Issues, and Options for Congress. R41744. Washington: Congressional Research Service, 2011.

HATCH, G. P. Critical Rare Earths - Global supply \& demand projections and the leading contenders for new sources of supply. Technology Metals Research, Carpentersville, 2011. HUMPHRIES, Marc. Rare earth elements: the global supply chain. Report for Congress. Congressional Research Service -USA. R41347. 2012.

KIGGINS, R. D. The Strategic and Security Implications of Rare Earths. In: KIGGINS, R. D. The Political Economy of Rare Earth Elements: Rising Powers and Technological Change. International Political Economy Series. United Kingdom: Palgrave Macmillan, 2015.

KIM, Jeonghoi. Recent Trends in Export Restrictions on Raw Materials, in OECD. The Economic Impact of Export Restrictions on Raw Materials. OECD Publishing, 2010. Disponível em: http://www.keepeek.com/Digital-Asset-Management/oecd/trade/ the-economic-impact-of-export-restrictions-on-raw-materials/recent-trends-in-exportrestrictions-on-raw-materials_9789264096448-4-en\#page1. Acesso em: 21 mar. 2016. KORINEK Jane; KIM, Jeonghoi. Export restrictions on strategic raw materials and their impact on trade and global supply. Organisation for Economic Co-operation and Development. OECD Trade Policy Working Paper n. 95. 29-Mar-2010.

LIMA, Paulo Cesar Ribeiro. Terras Raras: a importância de um plano estratégico. Estudos \& Pesquisas. Caderno AsLegis. Janeiro/abril. 2011. Disponível em: http://bd.camara. leg.br/bd/handle/bdcamara/11394. Acesso em: 30 jun. 2015.

LIMA, Paulo César Ribeiro. Terras Raras: Elementos Estratégicos para o Brasil. Senado Federal, 2012. Disponível em: http://www2.camara.leg.br/a-camara/altosestudos/ arquivos/EstudoMineraisEstratgicoseTerrasRaras.pdf. Acesso em: 10 set. 2013.

MARTINS, Tereza S.; ISOLANI, Paulo Celso. Terras raras: aplicações industriais e biológicas. Química Nova, v. 28, n. 1, 2005, p. 111-117

MAYER, Herbert; GLEICH, Benedikt. Measuring Criticality of Raw Materials: An Empirical Approach Assessing the Supply Risk Dimension of Commodity Criticality. Natural Resources, vol.6, 2015, p.56-78. Disponível em: http://www.scirp.org/journal/nr http://dx.doi.org/10.4236/nr.2015.61007. Acesso em: 24 abr. 2017.

MELO, Filipe Reis; DIAS, Hamana Karlla Gomes. A disputa por recursos estratégicos militares chega à OMC. Boletim Meridiano 47, v.16, n.151, 2015, p.37-45.

MEXÍA, Fernando. Los metales raros, el oro del tecnológico siglo XXI. El País, 17/01/2013. Disponível em: http://economia.elpais.com/economia/2013/01/17/ agencias/1358419709_572518.html. Acesso em: 21 mar. 2016.

MORRISON, Wayne M.; TANG, Rachel. China's Rare Earth Industry and Export Regime: Economic and Trade Implications for the United States. R42510. Washington: Congressional Research Service, 2012. 
NASSAR, N. T. et al. Criti- cality of the geological copper family. Environmental Science and Technology, vol. 46, n. 2, 2012, p. 1071-1078.

NATIONAL SCIENCE AND TECHNOLOGY COUNCIL. Committee on Environment, Natural Resources, and Sustainability Subcommittee on Critical and Strategic Mineral Supply Chains. Assessment of Critical Minerals: Screening Methodology and Initial Application. Washington: Executive Office of The President, March 2016.

ORSI, Carlos. Senado discute marco regulatório para exploração de terras raras. 2012. Disponível em: http:// www.tnsustentavel.com.br/noticia/8717/Senado + discute + m arco + regulatório + para + explorac são + de + terr as + raras. Acesso em: 12 dez. 2013.

UNITED STATES GEOLOGICAL SURVEY. Rare Earths Statistics and Information. Mineral Commodity Summaries, January 2017. Annual Publications. Disponível em: https:// minerals.usgs.gov/minerals/pubs/commodity/rare_earths/. Acesso em: 25 abr. 2017.

RISK List 2015. Minerals UK. 2015. Disponível em: http://www.bgs.ac.uk/mineralsuk/ statistics/risklist.html. Acesso em: 21 mar. 2016.

SELTENE, Erden. China verstärkt Kontrolle über Hightech-Metalle. Spiegel on Line, 09/04/2012. Disponível em: http://www.spiegel.de/wirtschaft/unternehmen/chinagruendet-wirtschaftsverband-fuer-seltene-erden-a-826373.html. Acesso em: 21 mar. 2016.

SERRA, Osvaldo Antonio. Terras raras: Brasil x China. Journal of the Brazilian Chemical Society, v.22, n.5, São Paulo, May 2011. Disponível em: http://www.scielo.br/scielo. php? script $=$ sci_arttext\&pid $=$ S0103-50532011000500001\&lng $=$ en\&nrm $=$ iso\&tlng $=$ pt. Acesso em: 12 dez. 2013.

SOUSA FILHO Paulo C. de; SERRA, Osvaldo A. Terras Raras no Brasil: histórico, produção e perspectivas. Química Nova, v. 37, n. 4, 2014, p.753-760.

TABELA periódica completa. Tabelaperiodicacompleta.com. 2017. Disponível em: https://www.tabelaperiodicacompleta.com/lantanideos/. Acesso em : 18 set. 2017.

TAGLIACARNE, Anna. Recuperare le Terre rare. Per non essere ostaggi della Cina. Corriere della Sera, 12/06/2012. Disponível em: http://www.corriere.it/scienze/12_giugno_12/ terrerare-riciclo-ostaggio-cina_b278c63e-b3e3-11e1-a52e-4174479f1ca9.shtml. Acesso em: 21 mar. 2016.

WEBER, David. Terres Rares: avenir industriel et future richesse de l'Europe? Puteaux: Les Éditions du Net, 2012.

WHITE, Garry; ROWLEY, Emma. China angers the world as battle for rare earth metals escalates. The Telegraph, 18/03/2012. Disponível em: http://www.telegraph.co.uk/ finance/commodities/9151608/China-angers-the-world-as-battle-for-rare-earth-metalsescalates.html. Acesso em: 21 mar. 2016.

ZHANG, S. Problems and Countermeasures of Rare Earth Industry in China. Canadian Social Science. Vol. 9, n .3, p. 9-14, 2013. Disponível em: http://www.cscanada.net/index. php/css/article/view/j.css.1923669720130903.Z1013/4250. Acesso em: 26 abr. 2017. 